\title{
Home-Based Primary Care for Homebound Older Adults: Literature Review
}

\author{
Chang-O Kim ${ }^{1,2}$, Soong-Nang Jang ${ }^{3}$ \\ ${ }^{1}$ Institute of Social Welfare, Sungkonghoe University, Seoul, Korea \\ ${ }^{2}$ Clinical Research Center, Yangji Hospital, Seoul, Korea \\ ${ }^{3}$ Red Cross College of Nursing, Chung-Ang University, Seoul, Korea
}

Corresponding Author:

Soong-Nang Jang, $\mathrm{PhD}$

https://orcid.org/0000-0003-2621-945X

Red Cross College of Nursing, Chung-

Ang University, 84 Heukseok-ro,

Dongjak-gu, Seoul 06974, Korea

Tel: +82-2-820-5806

Fax: +82-2-824-7967

E-mail: sjang@cau.ac.kr

Received: February 27, 2018

Revised: May 18, 2018

Accepted: May 28, 2018
Home-based primary care (HBPC) refers to the type of home care services which provide interdisciplinary primary care services with a comprehensive and continuous manner. Currently, it is getting much attention due to possess potential of converting primary care services from outpatient clinic to home, especially for those who are medically isolated including homebound older adults. This study examined a number of HBPCs introduced in the literature since 1990s, and summarizes the key factors with the analytic framework of 5Ps: purpose, patients, people, process, patterns. The results of this study emphasize that contents of primary care for older population should be different from those of the general population. This paper may be interpreted as the practice guideline of the following policy questions: "How can we design the HBPC if it is introduced in the nearest future?" In the future, it is necessary to have a heated debate concerning what is the most desirable primary care system for older adults. (Ann Geriatr Med Res 2018;22:62-72)

Key Words: Home care, Homebound older adults, Primary care system, Frailty, Interdisciplinary team

\section{INTRODUCTION}

Primary care refers to healthcare service which is provided by a physician of the first or the most frequently contact. ${ }^{1,2)}$ The term primary care was first used in the Dawson Report in 1920 in the United Kingdom. ${ }^{3)}$ In 1978, the Alma-Ata Declaration of the World Health Organization suggested the desirable components of primary health care. ${ }^{4)}$ A physician should provide first-contact healthcare services with a patient-centered perspective as well as comprehensive and collaborative cares to deal with various medical problems and patient needs. Also, this kind of care must be continued from the 'cradle to the grave.' In other words, the concept of 'family doctor' or 'regular doctor' has been evolved with the development of the term of primary care. However, in countries where the most medical services are offered by private sector with competitive manner, the realistic meaning of primary care might be rather different. For example, in South Korea, it is widely accepted that primary care is the almost same terminology of local private local private clinics, because the proportion of the proportion of the private sector to total number of healthcare institutions which provide medical services is $\left.94.4 \% .^{5}\right)$

However, when we narrow our focus to the target population as older adults, we may doubt whether the current local clinics in Korea are appropriate for central roles of primary care. In particular, once we take into account the steep rise in the number of homebound older adults who are virtually isolated and enable to mobilize, shouldn't we pursuit more active strategies of primary care? In fact, the United States and some other countries of the Organisation for Economic Co-operation and Development (OECD) countries are moving to reform the primary healthcare system based on this recognition. ${ }^{6-8)}$ Home-based primary care (HBPC) is emerging model of care as one of the alternatives to move patientcentered primary care from local outpatient clinics to the home. This study emphasizes that the primary care for older adults should be different from that of the general population. The most advanced medical care needed in 21st century is not in the highly technological services, paradoxically, but in the most analogue services of home care. ${ }^{9,10)}$ Therefore, in this study, we aim to provide a review of the literature on various home care services in OECD countries and to suggest which factors should be importantly considered if HBPC is newly introduced in South Korea. Specifically, 2 questions are focused: (1) What is the core contents of HBPC which are commonly described in literatures? (2) How can we design the HBPC if it is introduced in the nearest future in South Korea (or other countries with less matured primary care system)? 


\section{MATERIALS AND METHODS}

\section{Definition of Terms}

Home care refers to healthcare activities performed by a physician or healthcare provider by visiting a patient's home. In previous research, it is also called "home visit," "house call," "outdoor practice," or "home-based medicine." In Western history of medicine, home care was quite prevalent until the 20th century's begin. ${ }^{11)}$ Until the 1930s, in the United States, 40\% of entire medical practice were reported to have been performed at home. ${ }^{12)}$ This is because the hospital in the modern sense was established only in the early 20 th century. Since then, with the development of hospitals, the number of home visits has declined sharply, and a hospital-centered medical system has been formed in most countries after the mid-20th century. However, in recent 30 years, the importance of home care has been emphasized again. ${ }^{13,14)}$ Due to the change of people's thought and desire on medical care, demands for home care services has increased significantly.

HBPC refers to the type of home care services which provide interdisciplinary primary care services with a comprehensive and continuous manner. ${ }^{15)}$ It is known that the first HBPC model was developed in the Mount Sinai Visiting Doctor program in New York, USA, and it is known to be one of the most successful home care program applied in the US Department of Veterans Affairs in 1985. ${ }^{16)}$ Recently, the Agency for Healthcare Research and Quality (AHRQ), an evidence-based medical technology assessment agency, presented a more rigorous definition of HBPC (Table 1). According to the definition, HBPC has distinguished characteristics from other general home care services. To be called as HBPC, physicians should make his/her own visit to patient's home, not temporarily, and provide comprehensive healthcare or social services through interdisciplinary teams. In the present study, we will use the term HBPC according to the definition of AHRQ, which contains desirable natures of primary care as suggested in Table 1 during the process of home visiting.

\section{Sources of Information}

PubMed, MEDLINE and Cochrane Database were searched for articles published between January 1, 1990, and September 30, 2017 using the key phrases ("home-based primary care" or "home care" or "home visit" or "house call" or "outdoor practice" or "home-based medicine") and ("ageing" or "aging" or "aged" or "older" or "elderly"). Review articles and original research that related to the home care of broad meaning were examined. Also, gray literatures were collected through manual search. HBPC is not a service or program targeted only for the elderly. However, in this study, we focused to the HBPC programs which were targeted for community-dwelling or homebound older adults aged 65 year-olds or over. This study did not provide a critical review of the literature but presents examples of models that have been evaluated.

Table 1. Defining characteristics of home-based primary care models

\begin{tabular}{|c|c|c|}
\hline Require for this review & Optional & Excluded \\
\hline $\begin{array}{l}\text { 1. Visits by a primary care provider } \\
\text { Visits by a physician, nurse practitioner, or } \\
\text { physician assistant }\end{array}$ & $\begin{array}{l}\text { Additional visits } \\
\text { Nurses, physical therapists, social worker, } \\
\text { counselors, etc. }\end{array}$ & $\begin{array}{l}\text { Other models that do not include primary } \\
\text { care home visits. } \\
\text { Telephone call care only or nurse (or other } \\
\text { provider) care only. }\end{array}$ \\
\hline $\begin{array}{l}\text { 2. Visits to a patient's home } \\
\text { Home is defined as any noninstitutional } \\
\text { setting where patient resides. It can } \\
\text { include private houses or apartments, } \\
\text { adult homes, senior housing or assisted } \\
\text { living. }\end{array}$ & $\begin{array}{l}\text { Following patient across care setting } \\
\text { In hospital management and short-term } \\
\text { postacute rehabilitation }\end{array}$ & $\begin{array}{l}\text { Patients in institutions } \\
\text { Patients who live in nursing homes, prisons, } \\
\text { or long-term care hospitals }\end{array}$ \\
\hline $\begin{array}{l}\text { 3. Longitudinal management } \\
\text { The intention is to provide care for an } \\
\text { indefinite period until admission to an } \\
\text { institution, change in status, or death. }\end{array}$ & Not applicable & $\begin{array}{l}\text { Short term } \\
\text { One-time home visits or assessments, } \\
\text { hospital at home models in which care is } \\
\text { provided for an acute need and the patient } \\
\text { returns to previous primary care, or } \\
\text { transitional care, for a short defined period } \\
\text { (e.g., } 30 \text { to } 90 \text { days posthospitalization, or } \\
14 \text { days after surgery). }\end{array}$ \\
\hline $\begin{array}{l}\text { 4. Comprehensive primary care } \\
\text { Includes medical care for, and the } \\
\text { management of, chronic conditions and } \\
\text { disabilities, preventive care, providing } \\
\text { or arranging needed acute care and } \\
\text { environmental assessments. }\end{array}$ & $\begin{array}{l}\text { Inclusion of additional services such as } \\
\text { mental health services, palliative care, } \\
\text { long term services and supports or social } \\
\text { services } \\
\text { Assessment and management of serious } \\
\text { mental illness including depression. } \\
\text { Integration of palliative care or hospice } \\
\text { with home-based primary care. }\end{array}$ & $\begin{array}{l}\text { Single condition care or single topic risk } \\
\text { assessment } \\
\text { Fall risk assessments, programs that target a } \\
\text { single condition such as congestive heart } \\
\text { failure. }\end{array}$ \\
\hline
\end{tabular}

Adapted from Totten et al. AHRQ Publication No. 15(16)-EHC036-EF. Rockville (MD): Agency for Healthcare Research and Quality (US); 2016. ${ }^{16)}$ 


\section{Theoretical Framework}

HBPC is being considered as one of the alternatives of the primary care in several countries in order to improve medical accessibility and reduce medical cost especially targeted on homebound older adults. Lately, a number of reports and articles have been published concerning comprehensive care models for older adults at national, municipal, and neighborhood levels. ${ }^{16-20)}$ As a representative study, Boult et al. ${ }^{21)}$ reported the 15 "successful" models of care for older adults based on 123 high-quality studies which published from 1987 to 2008. According to the report, all fifteen models showed the evidence of improvement at least one of the following outcomes: quality of care, quality of life, functional autonomy, mortality or health service utilization (Table 2). Among the models, HBPC could be classified as preventive home visit or inter- disciplinary primary care or mixed one.

In this study, we use a clinical microsystem model which proposed by Olsan et al. ${ }^{22)}$ as the main analytic framework. This model was originally developed to answer the question, "How can we improve the quality of service in healthcare organizations?" According to this model, contents and quality of HBPC are determined through the interaction between the 5 components (5Ps): purpose, patients, people, process, patterns. First, the purpose of HBPC is related with the question, which concerns the value of home care: 'Why do we have to visit to a patient's home?' Second, HBPC is specially targeted to the patients of homebound older adults. It includes the family (caregiver) of the patients who gives support at home. Third, HBPC service is provided by the people of interdisciplinary team which is often composed of physicians, nurses, physical therapists, social workers, dietitians, and other kinds of healthcare specialists. Fourth, the process of HBPC is orga-

Table 2. Summary of evidence on 15 successful models of care

\begin{tabular}{|c|c|c|c|c|c|c|}
\hline Model & Studies & $\begin{array}{l}\text { Quality } \\
\text { of care }\end{array}$ & $\begin{array}{l}\text { Quality } \\
\text { of life }\end{array}$ & $\begin{array}{l}\text { Functional } \\
\text { autonomy }\end{array}$ & Survival & $\begin{array}{c}\text { Use/cost of } \\
\text { health services }\end{array}$ \\
\hline $\begin{array}{l}\text { 1. Interdisciplinary } \\
\text { primary care }\end{array}$ & $\begin{array}{l}1 \text { Meta-analysis } \\
2 \text { Reviews } \\
9 \text { RCTs } \\
3 \text { QE studies } \\
1 \text { XS time series }\end{array}$ & $\circ$ & $\circ$ & $\circ$ & $\circ$ & $\begin{array}{l}\mathrm{U}: \circ \\
\mathrm{C}: \circ\end{array}$ \\
\hline $\begin{array}{l}\text { 2. Care and case } \\
\text { management }\end{array}$ & $\begin{array}{l}12 \text { RCTs } \\
1 \text { QE study }\end{array}$ & $\circ$ & $\circ$ & $\circ$ & $\circ$ & $\begin{array}{l}\mathrm{U}: \circ \\
\mathrm{C}: \circ\end{array}$ \\
\hline 3. Disease management & $\begin{array}{l}1 \text { Review } \\
1 \text { Meta-analysis } \\
2 \text { RCTs }\end{array}$ & $\circ$ & $\circ$ & $\circ$ & $\circ$ & $\mathrm{U}: \circ$ \\
\hline 4. Preventive home visit & 3 Meta-analysis & NA & NA & $\circ$ & $\circ$ & $\mathrm{U}: \circ$ \\
\hline 5. CGA, GEM & $\begin{array}{l}10 \text { RCTs } \\
1 \mathrm{QE}\end{array}$ & $\circ$ & $\circ$ & $\circ$ & $\circ$ & $\mathrm{U}: \circ$ \\
\hline 6. Pharmaceutical care & 6 RCTs & $\circ$ & $\circ$ & NA & $\circ$ & $\mathrm{U}: \circ$ \\
\hline $\begin{array}{l}\text { 7. Chronic disease } \\
\text { self-management }\end{array}$ & $\begin{array}{l}1 \text { Meta-analysis } \\
10 \text { RCTs }\end{array}$ & NA & $\circ$ & $\circ$ & NA & $\begin{array}{l}\mathrm{U}: \circ \\
\mathrm{C}: \circ\end{array}$ \\
\hline 8. Proactive rehabilitation & $\begin{array}{l}4 \text { RCTs } \\
1 \text { QE studies }\end{array}$ & NA & $\circ$ & $\circ$ & $\circ$ & $\mathrm{U}: \circ$ \\
\hline $\begin{array}{l}\text { 9. Caregiver education } \\
\text { and support }\end{array}$ & $\begin{array}{l}2 \text { Meta-analysis } \\
3 \text { RCTs }\end{array}$ & NA & $\circ$ & $\circ$ & ND & $\begin{array}{l}\mathrm{U}: \circ \\
\mathrm{C}: \circ\end{array}$ \\
\hline 10. Transitional care & $\begin{array}{l}1 \text { Meta-analysis } \\
2 \text { RCTs }\end{array}$ & NA & $\circ$ & ND & $\circ$ & $\begin{array}{l}\mathrm{U}: \circ \\
\mathrm{C}:{ }^{\circ}\end{array}$ \\
\hline $\begin{array}{l}\text { 11. Substitutive } \\
\text { hospital-at-home }\end{array}$ & $\begin{array}{l}5 \text { RCTs } \\
1 \text { QE study }\end{array}$ & ND & $\circ$ & $\circ$ & ND & $\begin{array}{l}\mathrm{U}: \circ \\
\mathrm{C}: \circ\end{array}$ \\
\hline $\begin{array}{l}\text { 12. Early-discharge } \\
\text { hospital-at-home }\end{array}$ & 4 RCTs & NA & $\circ$ & $\circ$ & ND & $\mathrm{U}: \circ$ \\
\hline 13. Care in nursing home & $\begin{array}{l}5 \text { QE studies } \\
1 \text { RCT }\end{array}$ & $\circ$ & $\circ$ & $\circ$ & $\circ$ & $\begin{array}{l}\mathrm{U}: \circ \\
\mathrm{C}: \circ\end{array}$ \\
\hline $\begin{array}{l}\text { 14. Prevention and } \\
\text { management of } \\
\text { delirium }\end{array}$ & $\begin{array}{l}4 \text { RCTs } \\
2 \text { QE studies }\end{array}$ & $\circ$ & $\circ$ & $\circ$ & $\circ$ & $\begin{array}{l}\mathrm{U}: \circ \\
\mathrm{C}:{ }^{\circ}\end{array}$ \\
\hline $\begin{array}{l}\text { 15. Comprehensive } \\
\text { inpatient care }\end{array}$ & $\begin{array}{l}2 \text { Meta-analysis } \\
5 \text { RCTs } \\
1 \text { QE study }\end{array}$ & $\circ$ & $\circ$ & $\circ$ & $\circ$ & $\mathrm{U}: \circ$ \\
\hline
\end{tabular}

CGA, comprehensive geriatric assessment; GEM, geriatric evaluation and management; $\circ$, better outcomes; NA, not assessed; ND, no difference; RCT, randomized controlled trial; QE, quasi-experimental; XS, cross-sectional; U, use of health services; C, cost of health services. Adapted from Boult et al. J Am Geriatr Soc 2009;57:2328-37, with permission of Wiley. ${ }^{21)}$ 
nized by the various program components from enrollment to discharge, including interprofessional care meetings among the workforces as well as service programs. Fifth, the pattern of HBPC is about the performance how to measure the results of service provision. This study examined a number of HBPCs introduced in the literature since 2000s, and summarizes with the analytic framework of 5Ps.

\section{RESULTS}

\section{What is the Purpose of HBPC? (Purpose)}

The main objectives of the HBPC program, which is frequently mentioned in previous studies, are listed as follows.

(1) Promote medical accessibility for homebound older adults

(2) Provide integrated and continuous healthcare services

(3) Respect the value of patient's self-selection during the treatment process

(4) Reduce medical cost of older adults (e.g., unnecessary hospitalization)

First, improving accessibility to medically unreached groups such as homebound older adults is the most basic purpose of HBPC. Second, providing high-quality primary care services through home visits is an explicit goal pursued by a lot of programs of HBPC. Third, HBPC promotes patient-doctor relationships and naturally assures self-selection of patient and family during the treatment process. In particular, in the United Kingdom (UK) and Europe, respecting the value of self-selection is one of the most important goals of HBPC. Fourth, from a policy standpoint, HBPC is being tested within the goal of reducing medical cost among older adults.

These objectives contain paramount importance because they warn against the major trends of bio-industrialized medicine, which are heavily reliant on digital technology. In other words, the essence of medical care is still in the trust of the patient-doctor relationship. ${ }^{23,24)}$ It must be based on 'touch' rather than 'tech. ${ }^{9)}$ Clinical significance of contact is well known through previous studies of HBPC. Stuck and his colleagues ${ }^{17)}$ reported that there was a 33\% reduction in nursing home admission, when the number of home visits was conducted as many as 9 or more times. This suggests that HBPC has profound effects over the simple medication therapy. HBPC may promote population health through empowerment and/or social capital pathways. ${ }^{25,26)}$

There are some controversial issues whether HBPC should include 'respect for self-selection' in its purpose. ${ }^{14,19)}$ In fact, patient choice and participation must be respected as one of the most important values. ${ }^{25)}$ However, if we are looking at the historical background, these values are closely related to the modernizing trends of social service initiated in UK in 1998. At that time, the prime minister, Tony Blair emphasized the personalization and privatization of state-centered public services within the political context of the "third way. ${ }^{27)}$ In HBPC, the emphasis of selfselection is mean to determine the type and contents of service by the patients. ${ }^{14)}$ In this model, the patient could designate his or her family as a paid caregiver. There are 2 major criticisms of this consumer-directed care model. First, if the asymmetry of information and the monopoly structure of medical profession could not fundamentally be changed, self-selection in the medicine has no profound meaning beyond transferring all costs and responsibilities to the patient. ${ }^{28)}$ Second, the clinical effects of consumerdirected HBPC in the UK, the Netherlands, Germany, and Austria were significantly lower than that of North America in where consumer-directed services were not much prevailed. ${ }^{14,19)}$ In addition, emphasis on consumer choice has been reported to be ineffective in terms of reducing medical costs, as there exists evidence to increase service utilization. ${ }^{29)}$ However, satisfaction rate with patients and caregivers was significantly high. ${ }^{14)}$

\section{Who Are the Targets of HBPC? (Patients)}

The major target of HBPC is older adults especially in the following conditions.

(1) Functionally impaired persons

(2) Frail or isolated older adults

(3) Dying patients

(4) Patient's family and caregivers who provides supportive care

The patients most in needs of home care are those who have limited activities of daily living (ADL) in one or more domains, or who are largely dependent in instrumental ADL. According to Olsan et al. ${ }^{22)}$, HBPC subjects have an average ADL limit of 3.86. These severely impaired persons are generally eligible for long-term care facilities, but often refuse to admit to the facility due to willing to maintain their independent living in their own homes. Another major type of home care recipient is frail older adults or socially isolated older adults who are characterized as temporary impairment of geriatric function. Frailty refers to high-risk older adults who seem healthy at first sight but, due to have phenotypical characteristics of weakness, shrinking, poor endurance, slowness, and low physical activity, are at high risk of developing disability within months or years. ${ }^{30)}$ Isolated older adults refer to persons who are not actively participating in any kinds of social activities and, as a result, lacking supportive networks. ${ }^{31)}$ According to the recommendation of Independent at Home of Centers for Medicare and Medicaid Services in the United States, a person who has deficits in two or more $\mathrm{ADL}$ and has experience of hospitalization in the last year should be given priority to enroll in HBPC. ${ }^{16)}$ The advantage of this approach is that these patients are also those likely to have high health costs, making it feasible that cost saving could be realized in a relative short period of time.

How many people of homebound older adults are living in South Korea? Homebound status is often investigated 
Table 3. Prevalence of homebound older adults in recent epidemiologic studies

\begin{tabular}{lllcr}
\multicolumn{1}{c}{ Study } & Country & \multicolumn{1}{c}{ Area } & Subjects & Prevalence (\%) \\
\hline Umegaki et al. $^{32)}$ & Japan & Urban & 3,444 & 14.4 \\
Negrón-Blanco et al. $^{33)}$ & Spain & Rural & 1,622 & 9.8 \\
Cohen-Mansfield et al. $^{34)}$ & Israel & Nationwide & 1,609 & $17.7-19.5$ \\
Ganguli et al. $^{35)}$ & USA & Rural & 878 & 10.3 \\
Ornstein et al. $^{36)}$ & USA & Nationwide (medicare) & 7,609 & 5.6 \\
& & & (complete, 1.1; mostly, 4.5; semi-, 15.0) \\
\hline
\end{tabular}

through a self-questionnaire which measures the number of going outdoors or difficulties in going outside during the last week or month. ${ }^{32-35)}$ In recent study, Ornstein et al. ${ }^{36)}$ attempt to recategorize homebound persons into 2 groups, those who never (complete homebound) or rarely (mostly homebound) left the home and who could only left their home with assistance (semihomebound). Table 3 summarizes the prevalence of homebound older adults which were reported in epidemiologic studies in several countries. Although it seems rather varied, the prevalence rate of homebound older adults reported as 5\%-20\% in several OECD countries.

There is no single survey that has been conducted to estimate prevalence of homebound older adults in South Korea. Thus, the prevalence must be estimated by using indirect method. ${ }^{37)}$ The only exception is a survey of 3,024 female older adults who were registered in the Nurse-led Home-visiting Program in South Korea. ${ }^{38)}$ In this study, the prevalence of homebound older adults under 75 years old and over 75 years old were $22.8 \%$ and $40.2 \%$, respectively. According to this study, the prevalence of homebound older adults is estimated as $30.1 \%$, when we simply apply the population weight calculated from 2016 Population and Housing Census (Table 4). This rate must be overestimated when we consider the issues of sample selection and measurement error.

Table 4. Estimated prevalence rate of homebound older adults in South Korea

\begin{tabular}{lcc|}
\hline \multicolumn{1}{c}{ Variable } & Estimation & Prevalence (\%) \\
\hline $\begin{array}{l}\text { Homebound older adults (low } \\
\text { income) }\end{array}$ & $2,100,000$ & $30.1 \%^{*}$ \\
\hline $\begin{array}{l}\text { Isolated older adults } \\
\text { Frail older adults }\end{array}$ & $1,300,000^{\dagger}$ & 18.9 \\
\hline $\begin{array}{l}\text { Functionally impaired older } \\
\text { adults }\end{array}$ & $600,000^{\ddagger}$ & 8.3 \\
\hline
\end{tabular}

*Estimated prevalence rate according to the survey of female older adults who were registered in the Nurse-led Homevisiting Program in South Korea (applying population weight ${ }^{38)}$ ). 'Estimated number of isolated older adults according to the nationwide survey in Korea (applying 18.9\% [respondent rate who did not participate in any regular meeting during the last month] to older adults aged 65 and over ${ }^{40)}$ ). ${ }^{*}$ Estimated number of frail older adults according to the nationwide survey in Korea (applying 8.3\% [according to the Fried Criteria] to elderly population ${ }^{40)}$ ). ${ }^{\S}$ Number of survivors enrolled in Long-term Care Insurance in Korea (National Health Insurance Corporation ${ }^{39}$ ).
The prevalence rate could be estimated with other results of nationally representative survey (Table 4). As of September 2017, the number of survivor who are enrolled in the Long-Term Care Insurance in South Korea is 570,000 (8.1\% of total elderly population). ${ }^{39)}$ Considering the existence of noncoverage rate, the actual prevalence of functionally impaired older adults might be higher. In Korea, the prevalence of frail and isolated older adults are estimated to be 600,000 (8.3\% of total elderly population) and 1.3 million (18.9\% of total elderly population) respectively. ${ }^{40)}$ Thus, it is estimated that there are at least 600,000 or at most 2.1 million people who are both aged 65 or older and rarely left home. In other words, at least one-tenth of the older adults in South Korea is a medically isolated group, who could hardly meet a doctor other than a way of home visiting.

\section{Who Are Working for HBPC? (People)}

The main workforce of HBPC are described as follows. These people work full-time or part-time. But, they always work together as a team.

(1) Physician

(2) Nurse (nurse practitioner, physician assistance, clinical nurse specialist, etc.)

(3) Healthcare practitioner (physical therapist, occupational therapist, dietitian, etc.)

(4) Social worker

(5) Administrative assistant personnel (service coordinator, administrative manager, etc.)

(6) Volunteers

As a leader of the HBPC team, physicians are often geriatrics, family medicine, or internal medicine specialists. In the case of HBPC at university hospital settings, medical students or doctors in residency training program may participate in part-time visits. Nurses are core member of the HBPC. They are usually selected for an average ten years of clinical experience or for the certified as a geriatric nurse practitioner. In the United States, full-time case load for a nurse vary from 100 to 225 homebound older adults. ${ }^{22)}$ Typically half a day is devoted to home visits, and the average time per visit range from 30 minutes to 1 hour (the first visit requires 1 to 2 hours). Other healthcare provider can be configured differently depending on the primary purpose of HBPC. For example, in the House Calls for Seniors in Indianapolis, USA, social workers are working together with geriatricians and geriatric nurse 
practitioners as to build an interdisciplinary care team. ${ }^{41)}$ They develop a comprehensive social needs plan through a weekly patient care meeting. In a typical team meeting, lasting 90 minutes, up to 30 patients can be discussed. The team meeting is considered critical to the coordination of care and success of the House Calls program. This kind of model of integrative care has been reported as clinically effective, especially for the low-income older population. ${ }^{42)}$

The job satisfaction of the HBPC workforce importantly depends on how well the program achieves its goals and values. ${ }^{22)}$ For example, if successful outreach was made to meet a certain medically isolated person, or if a home care service can successfully prevent unnecessary hospitalization or nursing home admission, job satisfaction would be increased. A more important factor, however, is a close relationship with the patient (or family caregiver). This kind of compensation can only be gained through home visiting activities. ${ }^{43)}$ In addition, it is also important to ensure that HBPC workforce could take pride in his/her work because they are contributing to health equity and social justice. In the United States and Canada, participating in HBPC are gradually becoming an important coursework for medical education and training. ${ }^{44,45)}$

\section{What is the Program of HBPC? (Process)}

The major program components which consists HBPC are listed as follows.

(1) Screening and enrollment

(2) Comprehensive geriatric assessment (CGA)

(3) Interprofessional care meeting

(4) Establishing home visits

(5) 24-hour urgent telephone counseling

(6) Coordinating community services and resources

Referrals come from a variety of channels, including local private clinics, general hospitals (geriatric care unit), public healthcare center, home care center, hospice organizations, long-term care facilities, social welfare centers, churches, families, and individuals. Thereafter, screening process is performed by using the preset enrollment criteria. A care plan is developed based on the finding from the CGA which is often perform during the first visit by the geriatrician. The CGA is a multidimensional and interdisciplinary diagnostic process designed to determine an older person's medical conditions, mental health, functional capacity and social circumstances. ${ }^{46)}$ The purpose is to plan and carry out a holistic plan for treatment, rehabilitation, support and long-term follow-up. The CGA is core service of HBPC.

An interprofessional care meeting is another important component for operating successful HBPC. ${ }^{17,19,47)}$ Following initial data gathering by the CGA, the team should meet to discuss the patient's needs. Each meeting typically begins with short discipline-specific presentations followed by interactive discussion among professionals. ${ }^{46)}$ Thereafter, administrative manager of HBPC sets up a home visit schedule, and various services would be coordinated according to the result of the meeting. In meta-analysis, a clinical examination as part of the initial multidimensional evaluation had a significant effect on reducing functional decline of older adults by 56\% in home care settings. ${ }^{47)}$ Also, according to the systematic review, 3 core components are reported to be important in the 6 HBPC program which demonstrated clinical effectiveness: interprofessional care teams, regular interprofessional care meetings (at least once a week), and after-hours support. ${ }^{19)}$

Periodic home visits according to the care plan could prevent emergency department visit, unnecessary hospitalization, and admission to long-term care facilities. Often, more than 9 visits (at least once a month) are required in most of the HBPC programs. ${ }^{16)}$ If such visits are carried out by interdisciplinary teams, significantly effect of reducing functional decline and preventing nursing home admission could be observed. ${ }^{17)}$ However, the actual number of visits vary according to the workforce and financial circumstances of HBPC. For example, the House Calls Program in South California, USA, reported that the number of doctors' visits were high during the pilot phase, but gradually replaced with nurse practitioners' visits to lower the program costs per patient. ${ }^{48)}$ In another example, the House Calls for Seniors in Indianapolis, USA, reported that the number of home visits of social workers could be reduced by increasing the role of telephone counseling (e.g., 227 home visits and 3,048 phone calls per year for a single social worker). ${ }^{41)}$

Twenty-four-hour urgent telephone counseling is another essential service which may have been underreported but explicitly important to reduce emergency department visits and unnecessary hospitalization rates. ${ }^{19)}$ To do this, duty system to cover the night and weekend time is needed to set up. A typical example is the House Calls program in South California, which operates a HealthCare Partner's 24/7 Support Center, where triage nurses take the duty of emergency telephone counseling without cease. ${ }^{48)}$ In case of urgent situation, consultation with the doctor on duty is carried out as to instruct patient and/or family how to cope with the events. In some cases, emergency home visit is performed by the HBPC physician.

In addition, HBPC team should build a community network from the various resources in the neighborhood to create a therapeutic environment for the patient. This includes public healthcare centers, mental health centers, dementia support centers, welfare centers, regional office of the municipal government, churches, nongovernmental organizations, food bank, citizen's associations as well as HBPC's service programs (e.g., preventive home visiting program, nutritional support program, prehabilitation program). Community network does not occur overnight. Substantial efforts, such as regular interagency meeting, must be prepared to build up trust and efficient communication. Table 5 lists the detailed program components needed to provide effective HBPC service. $^{22)}$ 
Table 5. List of program components to support home-based primary care (HBPC) operation

\begin{tabular}{|c|c|}
\hline Contents & Detailed program components \\
\hline Healthcare services & $\begin{array}{l}\text { - Specialist for medical treatment (e.g., geriatric care unit) } \\
\text { - Therapeutic therapy (e.g., physical/occupational therapy, nutritional counseling) } \\
\text { - Pharmacist for drug management } \\
\text { - Mental health support } \\
\text { - Wound management } \\
\text { - Patient and family education } \\
\text { - Interpretation for foreigner }\end{array}$ \\
\hline Community services & $\begin{array}{l}\text { - Home-delivered meal service } \\
\text { - Pharmacy } \\
\text { - Transportation (e.g., free shuttle bus for the disabled, taxi for the disabled) } \\
\text { - Linkage to home care, hospitals, and Emergency Department } \\
\text { - Adult protective services (e.g., welfare center for the elderly) }\end{array}$ \\
\hline Standard of care & $\begin{array}{l}\text { - Guideline and protocol development } \\
\text { - Quality and safety management } \\
\text { - Regulatory requirements } \\
\text { - Practice evaluation } \\
\text { - Training program for HBPC workforce }\end{array}$ \\
\hline Communication & $\begin{array}{l}\text { - Medical record system (e.g., electronic or paper chart) } \\
\text { - Clinical information system } \\
\text { - Team meeting } \\
\text { - Messenger system } \\
\text { - Community network (e.g., partnership with local service providers) }\end{array}$ \\
\hline Coordination and coverage & $\begin{array}{l}\text { - Assess patients' eligibility and enrollment } \\
\text { - Scheduling home visits } \\
\text { - Telephone triage } \\
\text { - On-call and emergency coverage (e.g., 24-hour urgent telephone counseling) }\end{array}$ \\
\hline Workforce management & $\begin{array}{l}\text { - Staff scheduling } \\
\text { - Workload assessment } \\
\text { - Recruiting } \\
\text { - Licensure } \\
\text { - Program marketing }\end{array}$ \\
\hline Equipment and supply & $\begin{array}{l}\text { - Home visit bag supplies (e.g., stethoscope, dressing set, injectables) } \\
\text { - Car supplies (i.e., suture kits, catheter, and insertion kits) } \\
\text { - Durable medical equipment }\end{array}$ \\
\hline Financial and legal support & $\begin{array}{l}\text { - Optimizing practice performance } \\
\text { - Coding, billing (e.g., National Health Insurance Corporation, out-of-pocket payment) } \\
\text { - Contracting } \\
\text { - Malpractice } \\
\text { - Regulatory review }\end{array}$ \\
\hline Technical support & $\begin{array}{l}\text { - Diagnostic equipment (e.g., electrocardiogram, ultrasound scan, mobile x-ray) } \\
\text { - Lab testing (e.g., blood test, urinalysis) } \\
\text { - Telemedicine home monitoring }\end{array}$ \\
\hline Sustainability & $\begin{array}{l}\text { - Political advocacy } \\
\text { - Community engagement (e.g., local private clinics) } \\
\text { - Meeting with sponsors/stakeholders (e.g., parent organization) } \\
\text { - Grants and research }\end{array}$ \\
\hline
\end{tabular}

Adapted from Olsan et al. J Am Med Dir Assoc 2009;10:304-13, with permission of Elsevier. ${ }^{22)}$

\section{What is the Performance Indicators of HBPC? (Pat- terns)}

The key performance indicators of HBPC are listed as follows.
(1) Patient satisfaction
(2) Clinical effectiveness
(3) Utilization of medical services
(4) Medical cost

First, the basic performance indicator of HBPC is patient satisfaction. There are abundant of evidences that HBPC increases satisfaction among patients and caregivers. ${ }^{14,16,49)}$ It is often said that homebound older adults might be difficult to use the primary healthcare services if there were no HBPC program in their hometown..$^{50)}$ HBPC has also been known to be effective in reducing caregiver burden which occurs mostly during the process of unpaid care works by the family. ${ }^{51)}$ Most of the citizens living in the region where the HBPC pilot project was initiated hope the program to be continued. ${ }^{50)}$ 
HBPC should promote patients' health. In many studies, clinical effectiveness has been measured using the following outcome indicators: (1) mortality, (2) disability, (3) admission to long-term care facilities, (4) fall, (5) quality of life, and (6) caregiver burden. Other indicators such as depression, cognitive function, nutritional status, physical performance, and social support also can be measured. However, from a policy perspective, another important performance indicator is medical cost. Most of the studies, including systematic reviews and meta-analysis, measured performance of HBPC by using (1) emergency department visits, (2) unnecessary hospitalization, and (3) medical cost of older adults.

Can we tell how effective HBPC is for the homebound older adults? A number of systematic reviews and metaanalysis have been carried out and their main conclusions could be summarized as follows. ${ }^{14,16-19,47,49,52-56)}$ First, there are evidences that not every home care programs are shown to be effective. ${ }^{55}$ However, when we reduce the scope and focus to the HBPC program, which meets the definition in Table 1, there are evidences that HBPCs have significant effects on reducing hospitalizations, hospital days, emergency and specialty visits, while unclear effects were identified on hospital readmission and nursing home days. ${ }^{16,19)}$ Stall et al. ${ }^{19)}$ concluded that consecutive home visits by primary care provider and a comprehensive approach by multidisciplinary teams are key factors for the program's success. However, additional research is needed to conclude whether HBPC could lead to a decline in medical cost in South Korea (or other countries with less matured primary care system).

Second, HBPC shows effectiveness among frail older adults in particular. ${ }^{53,54,56)}$ A recent systematic review of HBPC reported that "complex patients - those at highest risk of hospitalization (sicker) or most frail - have the most potential to benefit from HBPC."16) This means that, in order to operate HBPC successfully, it is important to select the right person who are matched to the purpose of the program. Frail older adults might be the one of candidates. Third, especially from a financial standpoint, HBPC which combine both social and medical services are reported as more effective model. Oeseburg et al. ${ }^{18)}$ reported that cost-effective services could be provided in the socioeconomic model (also referred to as the patient advocacy case management model) which provided more diverse social services within a patient-centered perspective. In a similar vein, social workers are increasingly recognized as important workforce in the HBPC setting. ${ }^{41,42,48)}$

\section{DISCUSSION AND CONCLUSION}

HBPC is a novel type of home care program that can reduce emergency department visit and unnecessary hospitalization rates among homebound older adults by providing integrated and continuous primary care services. As the population ages, policy makers are getting more interest in HBPC to reform the primary healthcare system, because evidence from systematic reviews and meta-analysis shows clinical effectiveness. Also, HBPC has clear evidences that increase patients and caregivers' satisfaction. HBPC is anticipated to be further evolved in the following two directions. First, when if HBPC services are provided to the frail elderly, better results might be achieved in improving clinical outcome indicators, such as mortality, disability, fall, admission to long-term care facilities, quality of life, and caregiver burden. Second, when if HBPC are providing more diverse social services, better results might be achieve in reducing medical costs of older adults.

At least 600,000 of older adults (about 10\% among entire population aged 65 and over) are estimated as homebound who may not go freely outside to use local outpatients clinics in South Korea. They are medically isolated population who are obviously excluded from the primary care system if no HBPC programs are available in their nearest hometown. However, until now, there is no previous research of HBPC in South Korea. We could not find any single case report which meets definition of Table 1. South Korea has a history that the family doctor registration system was tried to be initiated in 1996, but failed completely. ${ }^{57,58)}$ Instead of reforming the entire primary care system, only nurse-led home care program was admitted to introduce in general hospital in 2001. ${ }^{59)}$ A transitional care model was adopted for patients after discharge from hospital, and physicians were not allowed to visit patients' home. As a result, only a few cases of doctor-led house call program have been reported in public healthcare setting or in small private clinics for the purpose of humanitarian outreach service. ${ }^{60,61)}$

Nevertheless, demands for physician's home visits are not even low in South Korea. According to the population survey, 88.6\% of Koreans answered that they need a regular doctor for their own needs, and 90.3\% answered that they need a regular doctor for their family's needs. ${ }^{62)}$ In addition, Song ${ }^{63)}$ reported that 85\% of employers, 81\% of employees, and 86\% of healthcare providers surveyed in 149 workplaces are willing to receive doctor-led workplace visiting services. Among older adults, demands for physician's visits might be further increased, because unmet medical needs are associated with age. ${ }^{64)}$ Recently, the metropolitan government of Seoul initiated the 'ChatDong'; Home Visit Project by nurses and social workers for entire citizens of aged 65 years old. It is acknowledged as an integrated type of case management (socioeconomic model) which provide high levels of support, although there is no explicit role of physician in the project. ${ }^{65}$

This article emphasize that contents of primary care for older adults should be different from that of the general population. From this point of view, the core contents of HBPC which are commonly observed in literatures are summarized. First, HBPC should be targeted primarily to homebound (or frail) older adults. Second, physicians should be included in the HBPC workforce to create inter- 
disciplinary care team. Third, CGA should be conducted at initial home visit and interprofessional care meeting should be held regularly. Fourth, specific performance indicators such as rates of emergency department visits and unnecessary hospitalization should be monitored. Fifth, the following operational strategies need to be introduced to reduce medical costs of older adults: (1) strengthening the capacity of visiting nurses, (2) adopting a socioeconomic case management model, and (3) operating a 24-hour urgent telephone counseling system. These are important factors that should be reflected in the initial design when if the HBPC pilot project is introduced in South Korea in the future.

HBPC is a healthcare model that is currently getting much attention due to the potential of converting primary care services from outpatient clinic to home. It is anticipated that the proportion of older adults age 80 and over will sharply increase in the nearest future, so that public health concerns will also arise for community-dwelling but virtually isolated older adults from the primary care system. There are mixed prospects whether future HBPCs will be able to completely replace outpatient-centered primary care among the specific population, or to become a type of service within another integrated (or collaborative) primary care model. ${ }^{16)}$ However, in South Korea, where there is little role of public healthcare sector in the primary care setting, HBPC may contain 'symbolic' meaning to show the public how importance of good primary care is needed for population health. ${ }^{15)}$ The essential nature of medical care is not in the high technology but in the close relationship between patients (and their family) and healthcare providers. HBPC is, above all, the best practical model that could illustrate this kind of trust. In the future, it is necessary to have a heated debate concerning what is the most desirable primary care system for older adults in South Korea. In addition, empirical evidences on HBPC are much more needed in detail.

Conflicts of Interest Disclosures: The researchers claim no conflicts of interest.

\section{ACKNOWLEDGMENTS}

This study was supported by a grant of the Seokchun Caritas Foundation (2016-1).

\section{REFERENCES}

1. Choi YJ, Ko BS, Cho KH, Lee JH. Concept, values, current status and prospect of primary care in Korea. J Korean Med Assoc 2013; 56:856-65.

2. Lee JH, Choi YJ, Volk RJ, Kim SY, Park HS, Park TH, et al. Defining the concept of primary care in South Korea using a Delphi method: secondary publication. Health Policy Manag 2014;24: 100-6.

3. Egwu IN. Update: primary care is not the same as primary health care, or is it? Fam Community Health 1984;7:83-8.

4. World Health Organization. Primary health care: 25 years after ALMA-ATA. Technical Paper EM/RC50/8. Cairo (Egypt): World Health Organization Regional Office for the Eastern Mediterranean; 2003.

5. Nam IS. Trend of public healthcare services in South Korea (20122016). Sejong (Korea): Ministry of Health and Welfare; 2017.

6. Epstein RM, Street RL Jr. The values and value of patient-centered care. Ann Fam Med 2011;9:100-3.

7. Rich EC, Lipson D, Libersky J, Peikes DN, Parchman ML. Organizing care for complex patients in the patient-centered medical home. Ann Fam Med 2012;10:60-2.

8. Arend J, Tsang-Quinn J, Levine C, Thomas D. The patient-centered medical home: history, components, and review of the evidence. Mt Sinai J Med 2012;79:433-50.

9. Kinosian B. Twenty-first century home-centered medicine: it's about the touch, not the tech.... J Am Geriatr Soc 2014;62:2433-5.

10. Lee JY, Lim JY. The prospect of the fourth industrial revolution and home healthcare in super-aged society. Ann Geriatr Med Res 2017;21:95-100.

11. Peitzman SJ. The Fielding H. Garrison lecture: "I am their physician": Dr. Owen J. Wister of Germantown and his too many patients. Bull Hist Med 2009;83:245-70.

12. Unwin BK, Tatum PE 3rd. House calls. Am Fam Physician 2011; 83:925-38.

13. Cho HJ. Current status of nurse-led and doctor-led home care in foreign countries. J Korean Acad Fam Med 2001;22:S348-53.

14. Low LF, Yap M, Brodaty H. A systematic review of different models of home and community care services for older persons. BMC Health Serv Res 2011;11:93.

15. DeCherrie LV, Soriano T, Hayashi J. Home-based primary care: a needed primary-care model for vulnerable populations. Mt Sinai J Med 2012;79:425-32.

16. Totten AM, White-Chu EF, Wasson N, Morgan E, Kansagara D, Davis-0'Reilly C, et al. Home-based primary care interventions. AHRQ Publication No. 15(16)-EHC036-EF. Rockville (MD): Agency for Healthcare Research and Quality (US); 2016.

17. Stuck AE, Egger M, Hammer A, Minder CE, Beck JC. Home visits to prevent nursing home admission and functional decline in elderly people: systematic review and meta-regression analysis. JAMA 2002;287:1022-8.

18. Oeseburg B, Wynia K, Middel B, Reijneveld SA. Effects of case management for frail older people or those with chronic illness: a systematic review. Nurs Res 2009;58:201-10.

19. Stall N, Nowaczynski M, Sinha SK. Systematic review of outcomes from home-based primary care programs for homebound older adults. J Am Geriatr Soc 2014;62:2243-51.

20. Low LF, Fletcher J. Models of home care services for persons with dementia: a narrative review. Int Psychogeriatr 2015;27:1593-600.

21. Boult C, Green AF, Boult LB, Pacala JT, Snyder C, Leff B. Successful models of comprehensive care for older adults with chronic conditions: evidence for the Institute of Medicine's "retooling for an aging America” report. J Am Geriatr Soc 2009;57:2328-37.

22. Olsan TH, Shore B, Coleman PD. A clinical microsystem model to evaluate the quality of primary care for homebound older adults. J Am Med Dir Assoc 2009;10:304-13. 
23. Arrow JJ. Uncertainty and the welfare economics of medical care. Am Econ Rev 1963;53:941-73.

24. Kim MJ. An exploratory study on the meaning of "the patient trusts the doctor'. J Korean Content Assoc 2017;17:415-23.

25. Heumann LF, McCall ME, Boldy DP. Empowering frail elderly people: opportunities and impediments in housing, health, and support service delivery. Westport (CT): Praeger; 2001.

26. Kawachi I, Subramanian SV, Kim D. Social capital and health. New York: Springer; 2008.

27. Newman J, Glendinning C, Hughes M. Beyond modernisation? Social care and the transformation of welfare governance. J Soc Policy 2008;37:531-57.

28. Axtell-Thompson LM. Consumer directed health care: ethical limits to choice and responsibility. J Med Philos 2005;30:207-26.

29. Grabowski DC. The cost-effectiveness of noninstitutional longterm care services: review and synthesis of the most recent evidence. Med Care Res Rev 2006;63:3-28.

30. Fried LP, Tangen CM, Walston J, Newman AB, Hirsch C, Gottdiener J, et al. Frailty in older adults: evidence for a phenotype. J Gerontol A Biol Sci Med Sci 2001;56:M146-56.

31. Kim CO, Sunwoo D. A frailty instrument to predict disability, institutionalization, and mortality: finding from the living profiles of older people survey. J Korean Gerontol Soc 2015;35:451-74.

32. Umegaki H, Yanagawa M, Nakashima H, Makino T, Kuzuya M. The prevalence of homebound individuals in the elderly population: a survey in a city area in Japan. Nagoya J Med Sci 2015;77:439-46.

33. Negrón-Blanco L, de Pedro-Cuesta J, Almazán J, RodríguezBlázquez C, Franco E, Damián J, et al. Prevalence of and factors associated with homebound status among adults in urban and rural Spanish populations. BMC Public Health 2016;16:574.

34. Cohen-Mansfield J, Shmotkin D, Hazan H. Homebound older persons: prevalence, characteristics, and longitudinal predictors. Arch Gerontol Geriatr 2012;54:55-60.

35. Ganguli M, Fox A, Gilby J, Belle S. Characteristics of rural homebound older adults: a community-based study. J Am Geriatr Soc 1996;44:363-70.

36. Ornstein KA, Leff B, Covinsky KE, Ritchie CS, Federman AD, Roberts L, et al. Epidemiology of the homebound population in the United States. JAMA Intern Med 2015;175:1180-6.

37. Gill TM. Disentangling the disabling process: insights from the precipitating events project. Gerontologist 2014;54:533-49.

38. Choi K, Park E, Lee IS. Homebound status and related factors according to age in female elders in the community. J Korean Acad Nurs 2012;42:291-301.

39. National Health Insurance Corporation. Statistics of long-term care insurance in Korea. Wonju (Korea): National Health Insurance Corporation; 2017.

40. Park MH, Ha JC, Shin IH, Kim HG, Lee SY, Cho JH, et al. The living profiles of older people survey 2008: the basic report. Seoul: Ministry of Health and Welfare Press; 2009.

41. Beck RA, Arizmendi A, Purnell C, Fultz BA, Callahan CM. House calls for seniors: building and sustaining a model of care for homebound seniors. J Am Geriatr Soc 2009;57:1103-9.

42. Counsell SR, Callahan CM, Clark DO, Tu W, Buttar AB, Stump TE, et al. Geriatric care management for low-income seniors: a ran- domized controlled trial. JAMA 2007;298:2623-33.

43. LoFaso V. The doctor-patient relationship in the home. Clin Geriatr Med 2000;16:83-94, ix.

44. Smith KL, Ornstein K, Soriano T, Muller D, Boal J. A multidisciplinary program for delivering primary care to the underserved urban homebound: looking back, moving forward. J Am Geriatr Soc 2006;54:1283-9.

45. Frank C, Wilson CR. Models of primary care for frail patients. Can Fam Physician 2015;61:601-6.

46. Reuben DB. Principles of gericatric assessment. In: Hazzard WR, Blass JP, Halter JB, Ouslander JG, Tinetti ME. Principles of geriatric medicine and gerontology. 5th ed. New York: McGraw-Hill; 2003. p. 99-110.

47. Huss A, Stuck AE, Rubenstein LZ, Egger M, Clough-Gorr KM. Multidimensional preventive home visit programs for communitydwelling older adults: a systematic review and meta-analysis of randomized controlled trials. J Gerontol A Biol Sci Med Sci 2008; 63:298-307.

48. Melnick GA, Green L, Rich J. House calls: California program for homebound patients reduces monthly spending, delivers meaningful care. Health Aff (Millwood) 2016;35:28-35.

49. Tappenden P, Campbell F, Rawdin A, Wong R, Kalita N. The clinical effectiveness and cost-effectiveness of home-based, nurse-led health promotion for older people: a systematic review. Health Technol Assess 2012;16:1-72.

50. Anetzberger GJ, Stricklin ML, Gauntner D, Banozic R, Laurie R. VNA HouseCalls of greater Cleveland, Ohio: development and pilot evaluation of a program for high-risk older adults offering primary medical care in the home. Home Health Care Serv Q 2006;25:155-66.

51. Muramatsu N, Mensah E, Cornwell T. A physician house call program for the homebound. Jt Comm J Qual Saf 2004;30:266-76.

52. Stuck AE, Siu AL, Wieland GD, Adams J, Rubenstein LZ. Comprehensive geriatric assessment: a meta-analysis of controlled trials. Lancet 1993;342:1032-6.

53. Beswick AD, Rees K, Dieppe P, Ayis S, Gooberman-Hill R, Horwood J, et al. Complex interventions to improve physical function and maintain independent living in elderly people: a systematic review and meta-analysis. Lancet 2008;371:725-35.

54. Daniels R, van Rossum E, de Witte L, Kempen GI, van den Heuvel W. Interventions to prevent disability in frail community-dwelling elderly: a systematic review. BMC Health Serv Res 2008;8:278.

55. Mayo-Wilson E, Grant S, Burton J, Parsons A, Underhill K, Montgomery P. Preventive home visits for mortality, morbidity, and institutionalization in older adults: a systematic review and metaanalysis. PLoS One 2014;9:e89257.

56. Dedeyne L, Deschodt M, Verschueren S, Tournoy J, Gielen E. Effects of multi-domain interventions in (pre)frail elderly on frailty, functional, and cognitive status: a systematic review. Clin Interv Aging 2017;12:873-96.

57. Chung HJ, Hwang LI, Seo SR, Kim CW. Current status and reform of primary care system in Europe - Implication to Korea. Seoul: National Health Insurance Corporation; 2007.

58. Lee JH, Kim CH, Kang KS; Members of Committee for the Model Conduction of Voluntary FDRP. The opinion of private family practitioners on the family doctor registration program and it's 
major services. J Korean Acad Fam Med 2001;22:1021-33.

59. Yeom CH. Current status and prospect of nurse-led and doctor-led home care in Korea. J Korean Acad Fam Med 2001;22:S354-5.

60. Hwang SW, Kang DJ, Kim MJ, Bae CY. Experiences in home visits. Korean J Prim Health Care 2001;7:3-26.

61. Kong KA, Baik IM, Chung YJ, Lee SH, Lee HS. Home visits in an office practice in Seoul. J Korean Acad Fam Med 2003;24:541-6.

62. Park SM, Choi EJ, Kim JJ, Park YK, Kim YS. Public perception of the need for regular family doctors, their major role, and appropriate training duration. Korean J Fam Pract 2013;3:124-31.
63. Song JS. Home visiting and prescription - applicability for health care. In: Conference proceeding of the Korean Society of Occupational and Environmental Medicine; 2009; p.336-50.

64. Hwang BD, Choi R. The prevalence and association factors of unmet medical needs by age group in the elderly. Korean J Health Serv Manag 2015;9:81-93.

65. Kim GY. Outcomes and tasks of the 1st stage of the chat-dong project. In: Conference Proceeding of Chat-Dong Project 2016. Seoul: Seoul Welfare Foundation, 2016. 